\title{
Change in the Mechanic Properties and Electrical Resistivity of High Water Backfill Material under Electrochemical Treatment
}

\author{
Dongdong Chen, ${ }^{1,2}$ Yaohui Sun $\mathbb{D}^{1},{ }^{1}$ Shengrong Xie $\mathbb{D},{ }^{1}$ En Wang, Xiaoyu Wu, \\ and Pengyu $\mathbf{Q i}^{{ }^{1}}$ \\ ${ }^{1}$ School of Energy and Mining Engineering, China University of Mining and Technology (Beijing), Beijing 100083, China \\ ${ }^{2}$ State Key Laboratory of Mining Response and Disaster Prevention and Control in Deep Coal Mine, \\ Anhui University of Science and Technology, Huainan, Anhui 232001, China
}

Correspondence should be addressed to Shengrong Xie; xsrxcq@163.com

Received 31 May 2020; Revised 1 September 2020; Accepted 9 September 2020; Published 18 September 2020

Academic Editor: Guoqiang Xie

Copyright ( $) 2020$ Dongdong Chen et al. This is an open access article distributed under the Creative Commons Attribution License, which permits unrestricted use, distribution, and reproduction in any medium, provided the original work is properly cited.

\begin{abstract}
To modify the mechanic properties of high water backfill material (HWBM) for its engineering application in mining backfill, a series of experiments were performed to investigate the effects of electrochemical treatment on the mechanic properties and electrical resistivity of the HWBM at the early age. Meanwhile, the effects of the potential gradient, power-on time, and water-cement ratio $(W / C)$ on electrochemical modification efficiency were investigated. The results show that the uniaxial compression strength (UCS), elastic modulus, and deformation modulus of the HWBM all first increased and then decreased after electrochemical treatment with the increasing of the potential gradient and power-on time. However, for the HWBM with different $W / C$, the UCS and electrical resistivity both increased the HWBM except when the $W / C$ was $3: 1$. The elastic modulus and deformation modulus of the samples both increased after electrochemical modification except when the $W / C$ was $4: 1$. Additionally, there is a positive correlation between the UCS and electrical resistivity in HWBM samples. Therefore, it is proved that the electrochemical technology is a potential method for improving the physicochemical properties of the HWBM.
\end{abstract}

\section{Introduction}

The double liquid high water backfill material (HWBM) is a novel cementitious backfill material in coal mine, which consists of calcium sulfoaluminate (CSA) cement, calcium silicate $\left(\mathrm{C}_{2} \mathrm{~S}\right)$, gypsum, calclime, additives, and water $[1,2]$. Because of the advantages of high liquidity, fast setting, and high early strength [2], the HWBMs have been used to backfill the gob areas and roadway in mine for the ground surface subsidence control [3-5]. However, the application of the HWBM is limited by the disadvantages of poor toughness, small compressibility, and high cost. Additionally, as the water-cement ratio (W/C) increases, the setting time increases and the uniaxial compression strength decreases in the HWBM $[1,4-6]$.

To improve the engineering properties and reduce the backfill cost, the modification of the HWBM has attracted much recent research interest. Meanwhile, vast experiments have been performed to investigate the influence of various additions on the hydration process and physicochemical properties of HWBMs. For example, the addition of fly ash can enhance the residual strength of HWBMs and reduce backfill cost, but the UCS decreases as the content of fly ash increases [7-10]. The addition of lithium carbonate or aluminum sulfate can enhance the compression strength and accelerate the hydration process of the $\operatorname{HWBM}[2,11]$. Additionally, the addition of river sand, gravel aggregate, and silica fume also can modify the mechanical properties of HWBMs [12, 13]. Meanwhile, the effects of water-cement ratio, gypsum-lime content, and additives on the performance of the HWBM also have been investigated by many scholars $[1,2,14-16]$. However, as a novel modified technique for improving the physical properties of rock and soil, electrochemical modification (ECM) of the HWBM has no reports. 
The use of the electrochemical method is a valid rock and soil modification technique that has been researched for many years. In the electrochemical treatment of rock and soil, a direct current (DC) electric field is applied to pass through the rock or soil mass, which causes charged species present in the soil or rock mass (cations and anions, polar water, and other charged particles) to migrate towards an oppositely charged electrode. Ultimately, the physicochemical properties of the soil or rock mass is modified significantly $[17,18]$. Nowadays, the electrochemical method has been successfully applied to many fields of geotechnical engineering, such as the electrochemical consolidation of weak rock [18-20], the electrochemical desalination of rock and soil [21-27], the electroosmotic consolidation of soils [28-34], and the electrochemical modification of the adsorption and desorption behavior of methane and water adsorption in anthracite [35-38]. Meanwhile, the electrochemical method also was applied to modify the mechanic properties of the fly-ash cemented backfill materials; they find that a power-on time of $180 \mathrm{~min}$ and a potential gradient of $1 \mathrm{~V} / \mathrm{cm}$ can enhance the strength and reduce the deformation of the fly-ash cemented backfill materials [39]. Additionally, ECM also was used in electroosmotic dewatering of mine tailings, electrochemical accelerated leaching of cement binders containing high volume fly ash, and the electrochemical chloride removal of cement paste subjected to $\mathrm{NaCl}$ and $\mathrm{Na}_{2} \mathrm{SO}_{4}$ attack [40-42]. These studies have proved that electrochemical treatment is an effective technique for the modification of the physicochemical properties of rock and soil mass. Meanwhile, the compression and deformation parameters of backfill materials are important factors for backfill mining $[43,44]$. However, the electrochemical modification of HWBM has not been reported to our knowledge. Hence, to fill the research gaps and enhance the performance of HWBM, we will focus on investigating the influence of electrochemical treatment on the strength deformation modulus, elastic modulus, and electrical resistivity of HWBMs.

Therefore, the objective of this paper is to investigate the influence of electrochemical treatment on mechanic properties and electrical resistivity of the HWBMs at an early age. Additionally, the influence of the potential gradient and power-on time on electrochemical modified efficiency of the HWBM and the electrochemical modification efficiency on the HWBMs with different $W / C$ were investigate. Meanwhile, the relationship between the UCS and electrical resistivity of the HWBM was proposed for its nondestructive testing in the hydration process.

\section{Materials and Method}

2.1. Materials. In this work, the HWBM was obtained from Hebei, China, which is composed of CSA cement, $\mathrm{C}_{2} \mathrm{~S}$ anhydrite, gypsum, and the compound additives. The HWBMs included two types of slurry, that is, material A
(CSA and $\mathrm{C}_{2} \mathrm{~S}$ cement clinker) and material B (anhydrite and gypsum). Figure 1 shows the main mineralogical compositions of materials $\mathrm{A}$ and $\mathrm{B}$ determined by the XRD test. The semiquantitative analysis results of mineralogical compositions of materials $\mathrm{A}$ and $\mathrm{B}$ were tabulated in Table 1.

2.2. Electrochemical Treatment Apparatus. Three sets of electrochemical experimental apparatuses were made in this study, and each set was composed of a DC power supply, a current meter, an electrolytic cell, electrodes, copper wires, and the HWBM samples. The schematic of electrochemical treatment applied to a HWBM is shown in Figure 2. The maximum output voltage is $150 \mathrm{~V}$ and the maximum output current is $5 \mathrm{~A}$ of the DC power supply (IT6933 A, ITECH Electronic Co. Ltd., Nanjing, China). The electrode was a round porous iron plate with a diameter of $50 \mathrm{~mm}$ and a thickness of $5 \mathrm{~mm}$. The electrolytic cell was an acrylic tube with an internal diameter of $50 \mathrm{~mm}$ and a wall thickness of $10 \mathrm{~mm}$, and both sides of the electrolytic cell consisted of an acrylic tube with an outer diameter of $50 \mathrm{~mm}$ and a rectangular acrylic box. Then, four threaded rods were used to connect and fix the electrolytic cell.

\subsection{Experimental Procedure}

2.3.1. Preparation of Samples. In this work, the ratio of material A to material B was $1: 1$ and the curing age was 7 days. Before the samples were prepared, a cylindrical mold with an inner diameter of $50 \mathrm{~mm}$ and a length of $200 \mathrm{~mm}$ was made to prepare the HWBM samples with diameters of $50 \mathrm{~mm}$ and lengths of $100 \mathrm{~mm}$.

Materials A and B were mixed and stirred with water, respectively, according to the designed water-cement ratio in Table 2. Then, slurry A and slurry B were placed into molds and stirred. After the initial setting time, the HWBM samples were demolded, and a plastic film was used to cover the samples for preventing weathering. Next, the samples were placed in a constant humidity and temperature room with a curing temperature of $20^{\circ} \mathrm{C}$ and a humidity of $95 \%$. Then, the samples were cured for 7 days. In this experiment, 48 samples were prepared as shown in Table 2 . The potential gradient $(P)$, power-on time $(T)$, and water-cement ratio $(W / C)$ are selected to be the factors to investigate the effect of electrochemical parameters and materials on the modified efficiency. The UCS, deformation modulus, elastic modulus, and electrical resistivity of the HWBMs curing for 7 days are taken as the experimental results.

2.3.2. Electrochemical Treatment. The HWBM samples were prepared as described before. Then, the samples were put into the acrylic tube of the electrolytic cell and the electrode plates were placed on both ends of the sample. Next, each 


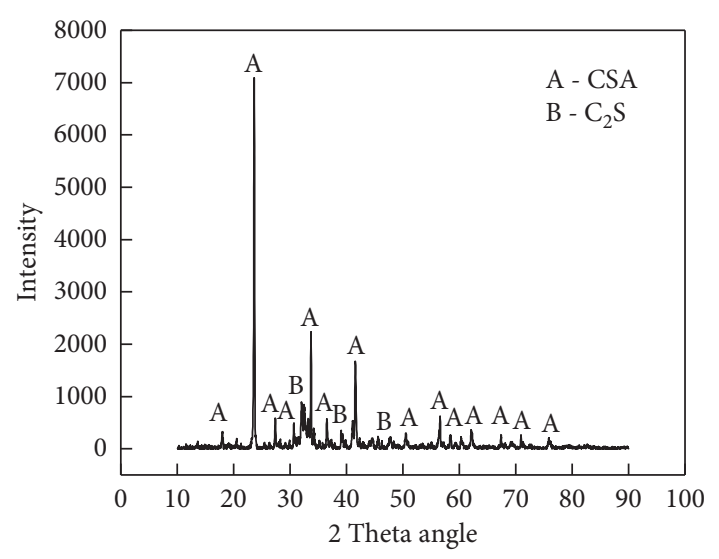

(a)

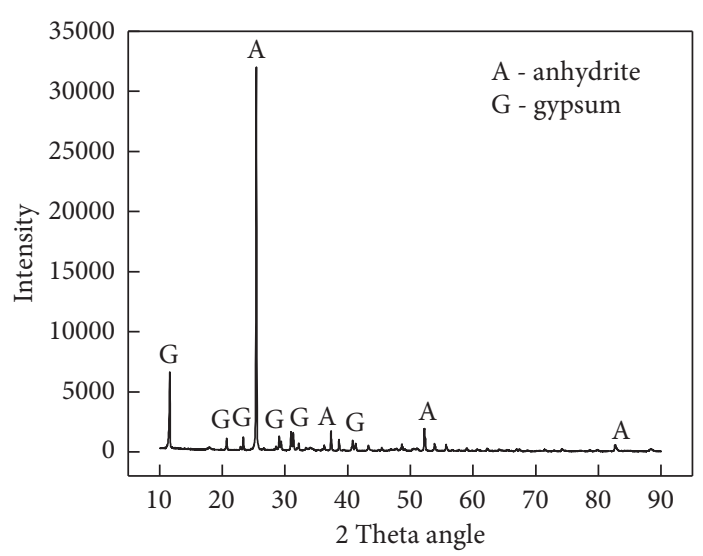

(b)

FIgURE 1: The XRD pattern of binder materials of the HWBM: (a) material A and (b) material B.

TABLE 1: Mineralogical composition and content of materials A and B in HWBM (\%).

\begin{tabular}{lcc}
\hline Phase & Material A & Material B \\
\hline CSA & 68.15 & 0 \\
$\mathrm{C}_{2} \mathrm{~S}$ & 34.85 & 0 \\
Anhydrite & 0 & 74.85 \\
Gypsum & 0 & 25.15 \\
\hline
\end{tabular}

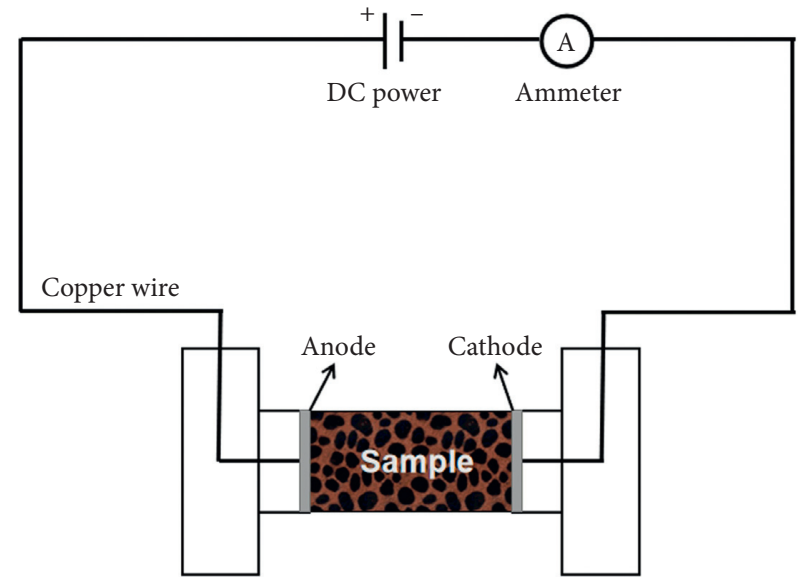

FIGURE 2: Schematic of the electrochemical treatment applied to the HWBM.

part of the electrochemical treatment apparatus was assembled as shown in Figure 3. The plastic film was covered on the electrolytic cell to minimize the contact area of the sample with air.

After the electrochemical treatment apparatus was assembled, the output voltage was adjusted according to the potential gradient, and, then, the output button of the DC power supply was pressed. In these experiments, the potential gradient and power-on time were set as shown in Table 2. After electrochemical treatment, the samples were cured for 7 days.
2.3.3. Electrical Resistivity Measurements. As shown in Figure 4, the electrical resistivity of the HWBM samples was measured by a MCH2816 A digital AC bridge (Shenzhen Meichuang Instrument Co. Ltd., China). Before measurement, the two ends of the samples were smoothed using a face-grinding machine, and the diameter and length of samples were measured. Then, the resistance of samples was measured at the measurement frequencies of $50 \mathrm{~Hz}, 100 \mathrm{~Hz}$, $500 \mathrm{~Hz}, 1 \mathrm{kHz}, 5 \mathrm{kHz}, 10 \mathrm{kHz}, 50 \mathrm{kHz}, 100 \mathrm{kHz}$, and $200 \mathrm{kHz}$, respectively.

The electrical resistivity of the HWBM sample is calculated from the following equation [45]:

$$
\rho=\frac{R \cdot S}{L}
$$

where $R$ is the electric resistance of samples in $\Omega, S$ is the cross-sectional area of the samples in $\mathrm{m}^{2}$, and $L$ is the length of the samples in $m$.

2.3.4. Uniaxial Compression Tests. The UCS of the HWBM samples were measured in a WAW-600B electrohydraulic servo universal testing machine (Tianshui Hongshan Testing Machine Co. Ltd., China) shown in Figure 5. According to the ISRM suggested methods [46], the loading rate of $2 \mathrm{~mm} /$ min was selected and shut down until the specimen was damaged. And the elastic modulus of the samples was calculated on the basis of the stress-strain curve.

\section{Results and Analysis}

3.1. The Effects of Electrochemical Modification on the Mechanic Properties of the HWBM. In this section, the effects of the potential gradient and power-on time on the UCS, deformation modulus, and elastic modulus of the HWBM were investigated. Additionally, the effect of electrochemical treatment on the mechanic properties of the HWBMs with different $W / C$ was investigated. 
TABLE 2: Experiment scheme of electrochemical modification on the HWBM.

\begin{tabular}{lccc}
\hline Number & $P\left(\mathrm{~V} \cdot \mathrm{cm}^{-1}\right)$ & $T(\min )$ & $W / C$ \\
\hline 1 & 0 & 0 & 0 \\
2 & 0.2 & 180 & $4: 1$ \\
3 & 0.5 & 180 & $4: 1$ \\
4 & 1.0 & 180 & $4: 1$ \\
5 & 2.0 & 180 & $4: 1$ \\
6 & 3.0 & 180 & $4: 1$ \\
7 & 0.2 & 60 & $4: 1$ \\
8 & 0.2 & 120 & $4: 1$ \\
9 & 0.2 & 240 & $4: 1$ \\
10 & 0.2 & 360 & $4: 1$ \\
11 & 0.2 & 540 & $4: 1$ \\
12 & 0.2 & 180 & $3: 1$ \\
13 & 0.2 & 180 & $5: 1$ \\
14 & 0.2 & 180 & $6: 1$ \\
15 & 0.2 & 180 & $7: 1$ \\
16 & 0.2 & 180 & $8: 1$ \\
\hline
\end{tabular}

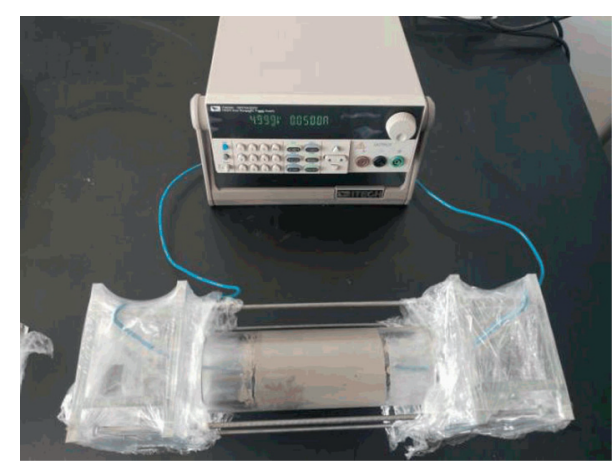

FIgURE 3: Electrochemical treatment on HWBM samples.

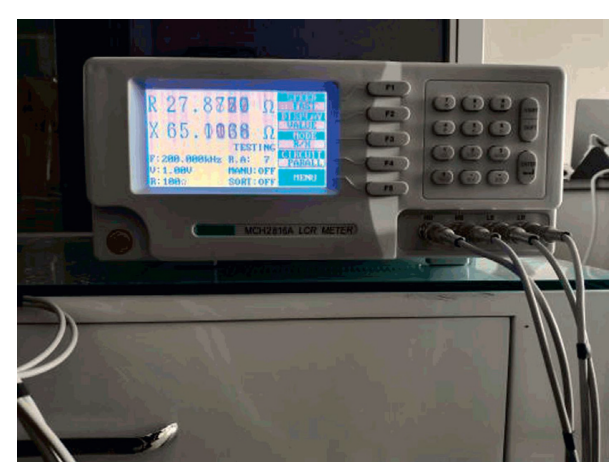

Figure 4: The MCH2816 A digital AC bridge.

3.1.1. Effects of Potential Gradient on Electrochemical Modification of HWBM. The stress-strain curves of the samples after electrochemical modification with different potential gradients are shown in Figure 6. This result indicates that the UCS of the samples was higher when the potential gradient was $0.2 \mathrm{~V} / \mathrm{cm}$ and $0.5 \mathrm{~V} / \mathrm{cm}$ while the UCS decreased as the potential gradient exceeded $0.5 \mathrm{~V} / \mathrm{cm}$. Additionally, the strain at the peak stress increased as the potential gradient increased. Furthermore, the effects of

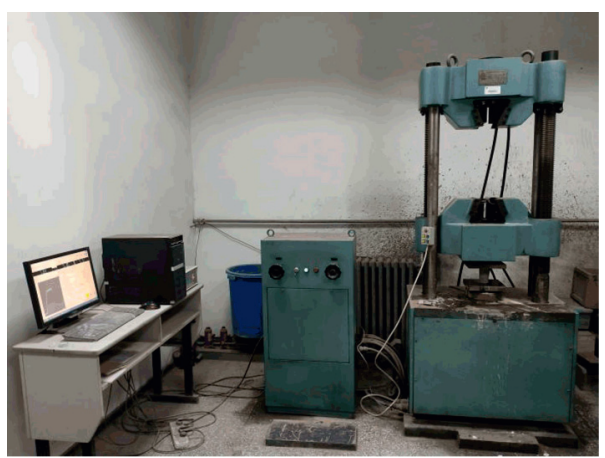

Figure 5: The uniaxial compression test bench.

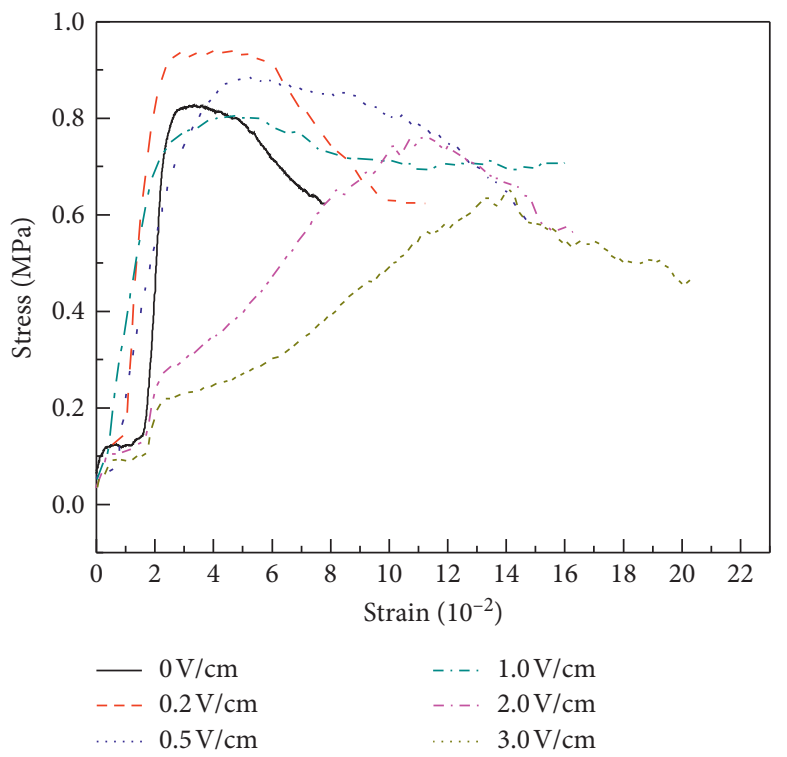

FIGURE 6: The change in the stress-strain curve of the samples after electrochemical modification with different potential gradients.

electrochemical treatment on the UCS, deformation modulus, and elastic modulus of the HWBM were investigated as shown in Figure 7.

As shown in Figure 7, the change in the peak strength, elastic modulus, and deformation modulus of the HWBMs after electrochemical modification with different potential gradients shows the following:

(1) When the potential gradient was $0.2 \mathrm{~V} / \mathrm{cm}$ and $0.5 \mathrm{~V} /$ $\mathrm{cm}$, the UCS of the HWBM increased by $10.78 \%$ and $7.22 \%$, respectively; when the potential gradient was $1.0 \mathrm{~V} / \mathrm{cm}, 2.0 \mathrm{~V} / \mathrm{cm}$, and $3.0 \mathrm{~V} / \mathrm{cm}$, the UCS of the HWBM decreased by $6.37 \%, 7.98 \%$, and $21.97 \%$, respectively. This result indicates that treatment with a weak electric field (less than $0.5 \mathrm{~V} / \mathrm{cm}$ ) can reinforce the strength of HWBMs.

(2) When the potential gradient was $0.2 \mathrm{~V} / \mathrm{cm}$, the elastic modulus of the samples increased by $25.01 \%$; as the potential gradient increased, the elastic modulus of the samples decreased from $45.12 \%$ to $67.26 \%$, $90.35 \%$, and $93.72 \%$, respectively. 


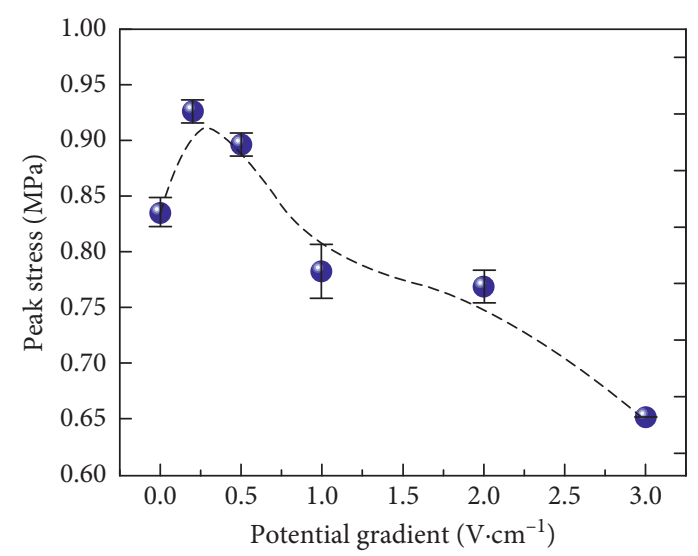

(a)

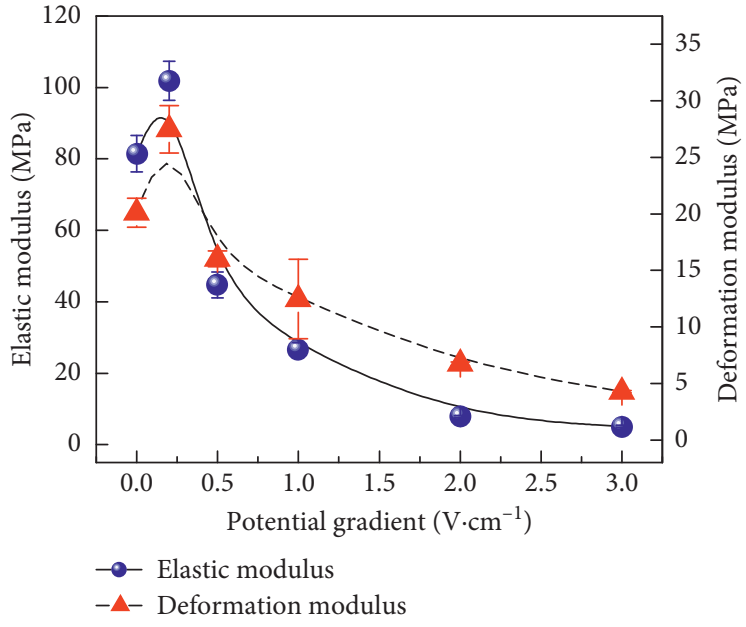

(b)

Figure 7: The change in (a) peak strength and (b) elastic modulus and deformation modulus of samples after electrochemical modification with different potential gradient.

(3) When the potential gradient was $0.2 \mathrm{~V} / \mathrm{cm}$, the deformation modulus of the HWBM samples increased by $36.78 \%$; with the increasing of the potential gradient, the elastic modulus of the samples decreased from $20.29 \%$ to $37.96 \%, 66.38 \%$, and $78.78 \%$, respectively. These results show that the electrochemical treatment can significantly alter the plastic deformation capacity of the HWBM samples.

Therefore, according to the change in the stress-strain curves, peak strength, and elastic modulus of the samples after electrochemical modification with different potential gradients, $0.2 \mathrm{~V} / \mathrm{cm}$ is the optimal potential gradient for electrochemically modifying the HWBM, which can simultaneously enhance the mechanic properties of the HWBM.

\subsubsection{Effects of Power-On Time on Electrochemical Modifi-} cation of the HWBM. To investigate the effect of the poweron time on electrochemical modification efficiency of the HWBM, the potential gradient of $0.2 \mathrm{~V} / \mathrm{cm}$ and $W / C$ of $4: 1$ were applied. Then, the power-on time was set as in Table 2.

Figure 8 shows that the residual strength of the HWBM samples increased with the increase of the power-on time after electrochemical modification. And the stress at the peak strain increased when the power-on time was more than $120 \mathrm{~min}$. Additionally, after electrochemical treatment, the peak stress of the HWBM samples all increased. Furthermore, the peak strength, deformation modulus, and elastic modulus of the HWBM samples were calculated.

Figure 9(a) shows that the peak strength of the samples increased by $5.89 \%, 6.86 \%, 10.79 \%, 11.40 \%, 13.41 \%$, and $3.01 \%$, respectively, after electrochemical modification when the power-on time increased from $1 \mathrm{~h}$ to $2 \mathrm{~h}, 3 \mathrm{~h}, 4 \mathrm{~h}$, and $6 \mathrm{~h}$ to $9 \mathrm{~h}$. It indicates that the UCS of the HWBM first increased and then decreased with the increase of power-on time while the extreme point appeared in the power-on time of $6 \mathrm{~h}$.
Additionally, as shown in Figure 9(b), the deformation modulus and elastic modulus of the samples also first increased and then decreased. However, the extreme point appeared in the power-on time of $3 \mathrm{~h}$ while the deformation modulus and elastic modulus of the HWBM receiving the electrochemical treatment increased by $36.78 \%$ and $25.01 \%$, respectively.

Combined with the variation of the stress-strain curve, peak strength, deformation modulus, and elastic modulus of the HWBM samples after electrochemical treatment with different power-on time and considering the need of engineering practice for the strength and deformation ability of HWBM, the optimum power-on time of $3 \mathrm{~h}$ was selected to investigate the effect of electrochemical treatment on the mechanic properties of HWBMs with different $W / C$.

\subsubsection{Effects of Electrochemical Modification on Mechanic} Properties of the HWBMs with Different W/C. Figure 10 shows the stress-strain curves of the HWBM with different $W / C$ before and after electrochemical modification. It can be observed that the UCS of HWBMs decreased as the W/C increased; this result is consistent with previous research $[1,6]$. Additionally, compared with the HWBM samples with a $W / C$ of $3: 1$, the residual strength of the HWBM increased with the increase of $W / C$. Meanwhile, the residual strength of the samples with different $W / C$ all increased after electrochemical modification.

Figure 11 shows the peak strength, deformation modulus, and elastic modulus of the HWBM samples with different $W / C$. It can be seen that the UCS, deformation modulus, and elastic modulus of the HWBMs all decrease with the creasing of $W / C$. However, after electrochemical treatment, the UCS of the HWBM increased by $10.78 \%$, $7.05 \%, 9.34 \%, 16.67 \%$, and $12.41 \%$, respectively as the $W / C$ increased from $4: 1,5: 1,6: 1,7: 1$, and $8: 1$ while the peak strength of the samples decreased by $12.51 \%$ as the $W / C$ was 


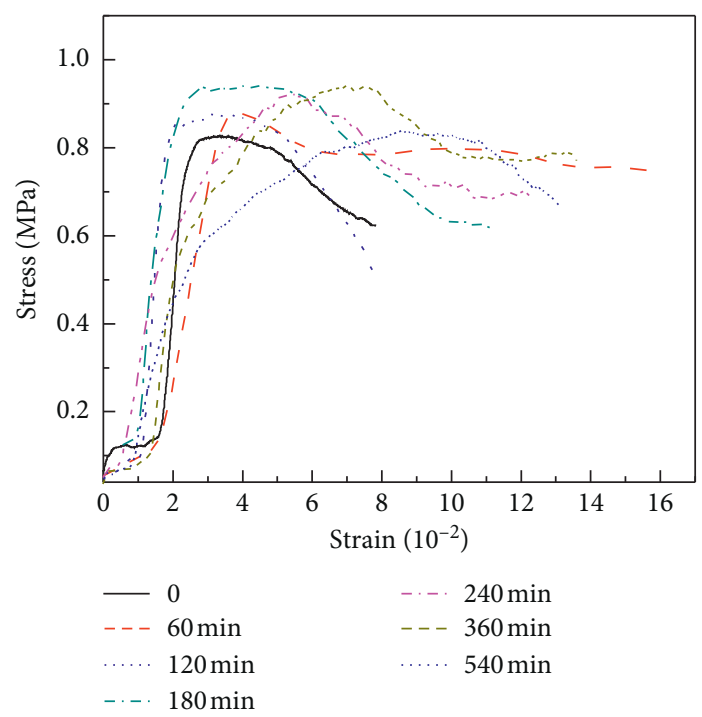

FIgURE 8: The change in the stress-strain curve of the samples after electrochemical modification with different power-on times.

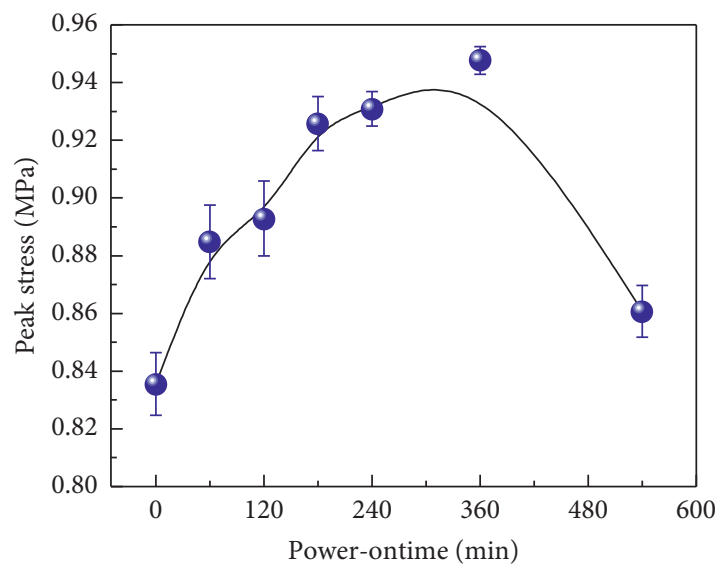

(a)

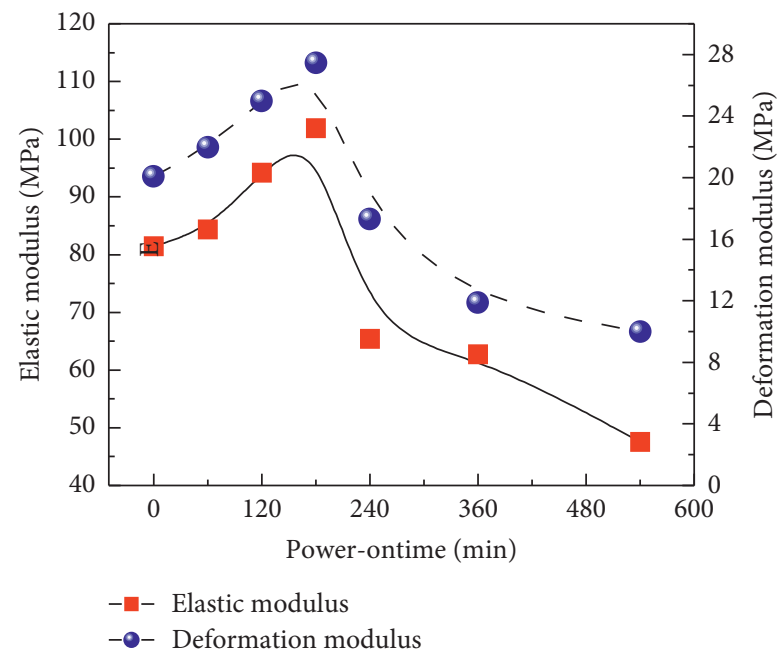

(b)

Figure 9: The change in (a) the peak strength, (b) elastic modulus, and deformation module of HWBM samples after electrochemical modification with different power-on times.

$3: 1$. Additionally, the deformation modulus and elastic modulus of the HWBMs decreased significantly after receiving the electrochemical treatment except when the $W / C$ was $4: 1$. It indicates that the electrochemical treatment can significantly alter the deformation modulus and elastic modulus of the HWBMs.

These results show that the UCS of the HWBM decreased when the $W / C$ was $3: 1$ while increasing as the $W / C$ was more than $4: 1$. However, the deformation modulus and elastic modulus decreased with the increase of $W / C$ except when the $W / C$ was $4: 1$. Hence, combined with the result of Sections 3.1.1 and 3.1.2, it can be found that the electrochemical modification can effectively enhance the UCS and residual strength and alter the plastic deformation capacity of the HWBM with different $W / C$ with the potential gradient of $0.2 \mathrm{~V} / \mathrm{cm}$ and the power-on time of $3 \mathrm{~h}$.
3.2. Effects of Electrochemical Treatment on the Electrical Resistivity of HWBMs. The electrical resistivity has been applied to evaluate the hydration process and mechanic properties of the cement based material for many years [47-50]. Thus, in these experiments, the electrical resistivity of the samples was used to study the relationship between the electrical resistivity and strength in the HWBM.

As shown in Figure 12, it can be observed that the electrical resistivity of the HWBM decreased with the increase of the measurement frequency while tending to stability as the frequency exceeded $50 \mathrm{KHz}$. This result indicates that lower measurement frequency can lead to the instability of the test, and this is consistent with a previous study [49]. Therefore, the measurement frequency of $200 \mathrm{kHz}$ was selected to investigate the effects of 


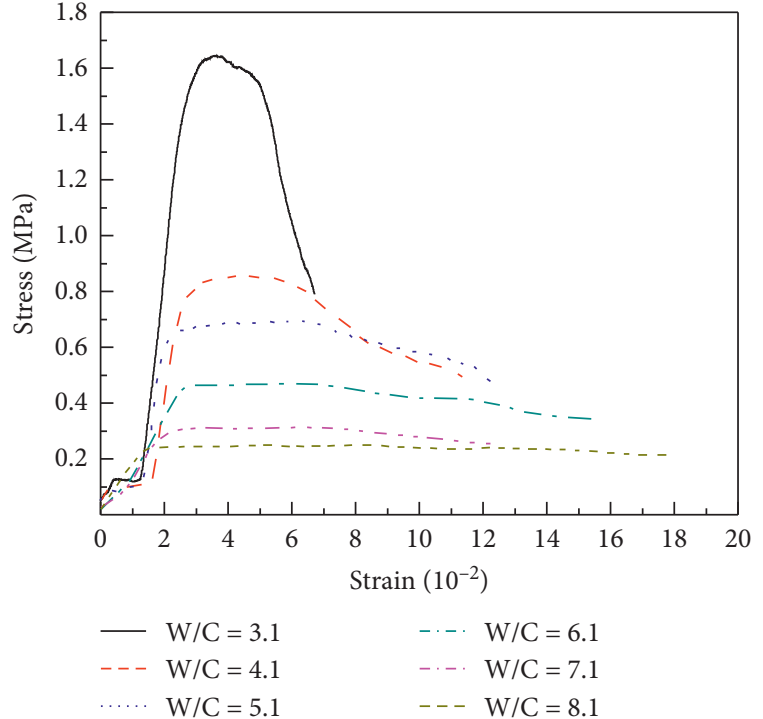

(a)

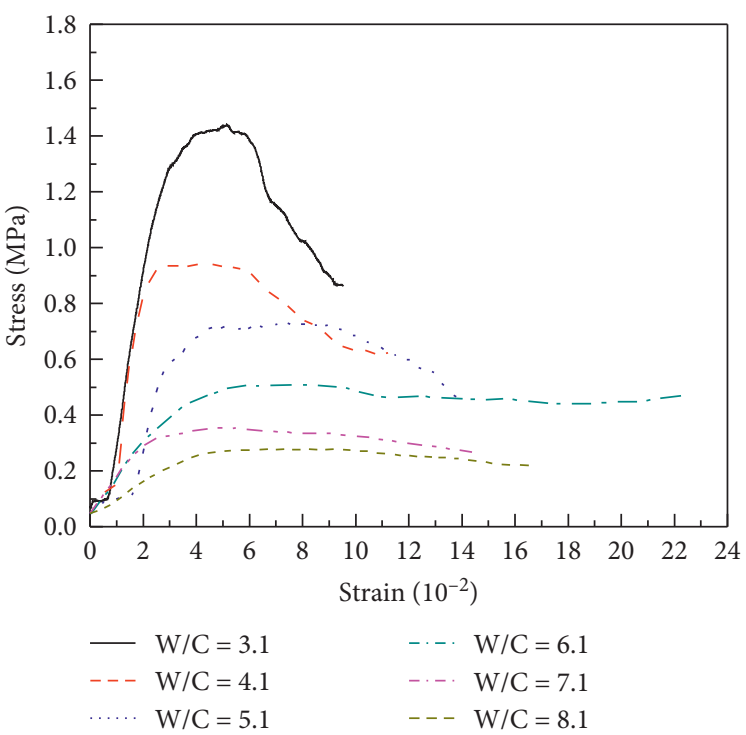

(b)

Figure 10: Stress-strain curves of the HWBM samples with different W/C: (a) untreated samples and (b) modified samples.

electrochemical modification on the electrical resistivity of the HWBM.

Figure 13(a) shows the variation of the electrical resistivity of the HWBM after electrochemical modification. It can be observed that the electrical resistivity of the samples first increased and then decreased with the increase of the potential gradient; the extreme point appeared in the potential gradient of $0.2 \mathrm{~V} / \mathrm{cm}$. Additionally, as shown in Figure 13(b), the electrical resistivity of the HWBM also first increased and then decreased as the power-on time increased from $1 \mathrm{~h}$ to $9 \mathrm{~h}$, and the extreme point occurred when the power-on time was $6 \mathrm{~h}$. These results are consistent with the variations of the peak strength shown in Figures 7 (a) and $9(\mathrm{a})$.

Figure 13(c) shows the variation of the electrical resistivity of the HWBM with different $W / C$ before and after electrochemical modification. It can be observed that the electrical resistivity of the HWBM decreased with the increase of the $W / C$. Additionally, the electrical resistivity of the HWBM increased after electrochemical modification except when the $W / C$ was $3: 1$.

In summary, the variation of the electrical resistivity of the HWBM is approximately consistent with the change of the UCS. Therefore, it can be inferred that there is a positive correlation between the UCS and electrical resistivity in the HWBM.

\subsection{The Correlation between UCS and Electrical Resistivity of} the HWBM. As with the mechanic properties, the electrical resistivity of rock and soil also is inherently determined by its chemical composition, pore structure, and particle size. Thus, there is possibly a strong correlation between the electrical resistivity and mechanical properties of rock and soil. Furthermore, the electrical resistivity has been successfully applied to evaluate the mechanic properties of cement based materials, such as the linear correlation between the electrical resistivity and compressive strength of cemented soil and zinc-contaminated soil solidified by cement $[47,48]$, the linear correlation between the electrical resistivity and the void ratio in undisturbed soil [49], the negative exponential relationship between the apparent resistivity and UCS in reinforced concrete [50], and the logarithmic relationship between the electrical resistivity and UCS in cemented backfill mass [51]. However, there are no reports demonstrating the correlation between the UCS and electrical resistivity of HWBMs at present.

Figure 14 shows the relationship between the UCS and the electrical resistivity of the HWBM. According to the fit curve and the fitting function as shown in equation (2), it can be inferred that there is a linear positive correlation between the UCS and electrical resistivity in the HWBM:

$$
\begin{array}{r}
\sigma=-0.08576+0.049252 \rho, \\
R^{2}=87.162 \%,
\end{array}
$$

where $s$ is the UCS of the HWBM and $\rho$ is the electrical resistivity of the HWBM.

However, this correlation is weaker due to the $R^{2}$ of $87.162 \%$. Thus, it is still necessary to carry out a lot of tests to confirm the correlation and, carry out quantitative characterization of this relationship, and provide the experimental and theoretical basis for the nondestructive testing of the hydration process and mechanical properties of the HWBM.

\section{Discussion}

In this work, the electrochemical modification of the early age HWBM was performed. And the potential gradient, 


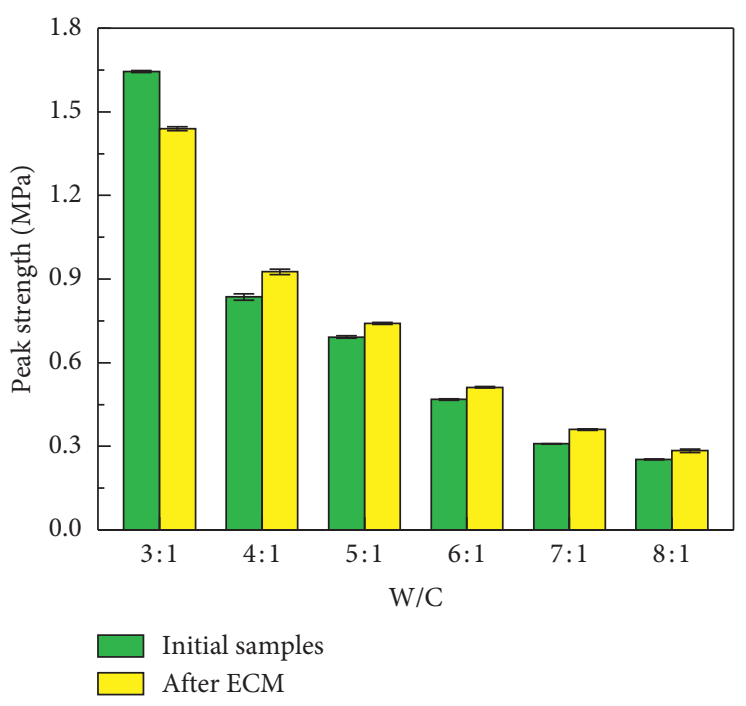

(a)

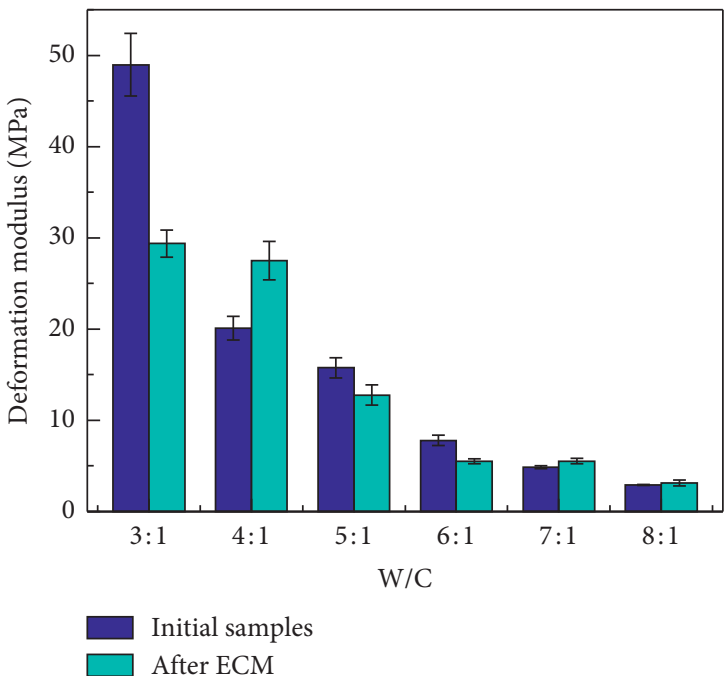

(b)

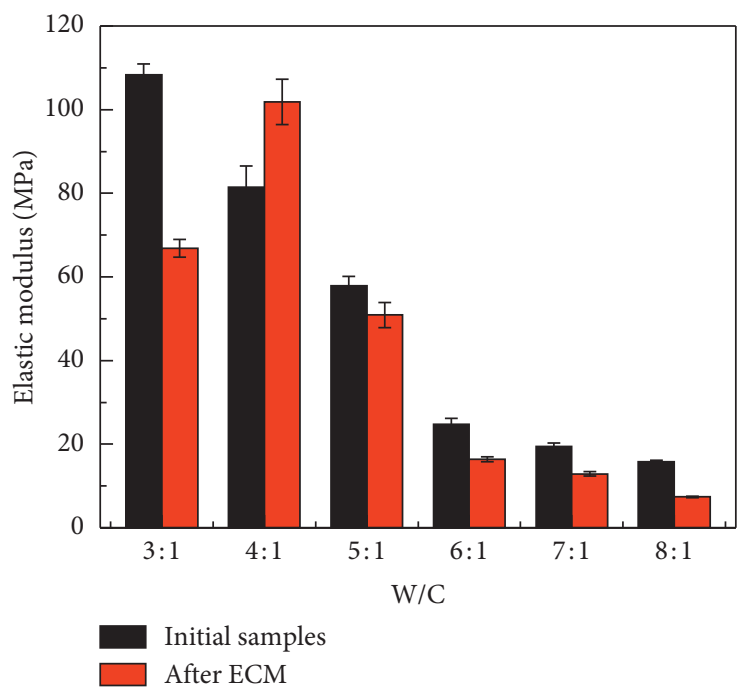

(c)

Figure 11: The change of elastic module of samples with different $W / C$ after electrochemical modification.

power-on time, and $W / C$ were taken as the main variables to investigate variation in the UCS, deformation modulus, elastic modulus, and electrical resistivity of the HWBM under DC electric field. The experimental results indicated that the electrochemical action of lower potential gradient and shorter power-on time can effectively enhance the UCS and deformation ability of HWBMs, which is consistent with the result of the electrochemical modification in the fly-ash cemented filling materials [39]. In addition, there is a positive correlation between the electrical resistivity and UCS in HWBMs, which indicates that the electrical resistivity of the HWBMs can evaluate its hydration process and strength in a certain sense [52].

4.1. Hydration Process of the HWBM. In the HWBM, the main hydration process in CSA clinker is as in equations (3) and (4), and the ettringite $\left(3 \mathrm{CaO} \cdot \mathrm{Al}_{2} \mathrm{O}_{3} \cdot 3 \mathrm{CaSO}_{4} \cdot 32 \mathrm{H}_{2} \mathrm{O}\right)$ and aluminum gel $\left(\mathrm{Al}_{2} \mathrm{O}_{3} \cdot 3 \mathrm{H}_{2} \mathrm{O}\right)$ as in equation (3) are formed when the gypsum is enough $[2,53,54]$ :

$$
\begin{array}{r}
3 \mathrm{CaO} \cdot 3 \mathrm{Al}_{2} \mathrm{O}_{3} \cdot \mathrm{CaSO}_{4}+2\left(\mathrm{CaSO}_{4} \cdot 2 \mathrm{H}_{2} \mathrm{O}\right)+36 \mathrm{H}_{2} \mathrm{O} \longrightarrow \\
3 \mathrm{CaO} \cdot 3 \mathrm{Al}_{2} \mathrm{O}_{3} \cdot \mathrm{CaSO}_{4} \cdot 32 \mathrm{H}_{2} \mathrm{O}+2\left(\mathrm{Al}_{2} \mathrm{O}_{3} \cdot 3 \mathrm{H}_{2} \mathrm{O}\right) \\
2 \mathrm{CaO} \cdot \mathrm{SiO}_{2}+\mathrm{nH}_{2} \mathrm{O} \longrightarrow \mathrm{C}-\mathrm{S}-\mathrm{H}+\mathrm{Ca}(\mathrm{OH})_{2}
\end{array}
$$

However, as shown in equation (5), the $\mathrm{AFm}$ $\left(3 \mathrm{CaO} \cdot \mathrm{Al}_{2} \mathrm{O}_{3} \cdot \mathrm{CaSO}_{4} \cdot 12 \mathrm{H}_{2} \mathrm{O}\right)$ would be formed when the gypsum is not sufficient. With the addition of the $\mathrm{CaO}$ and gypsum, additional ettringite will be formed as shown in equation $(6)[2,53,54]$ : 


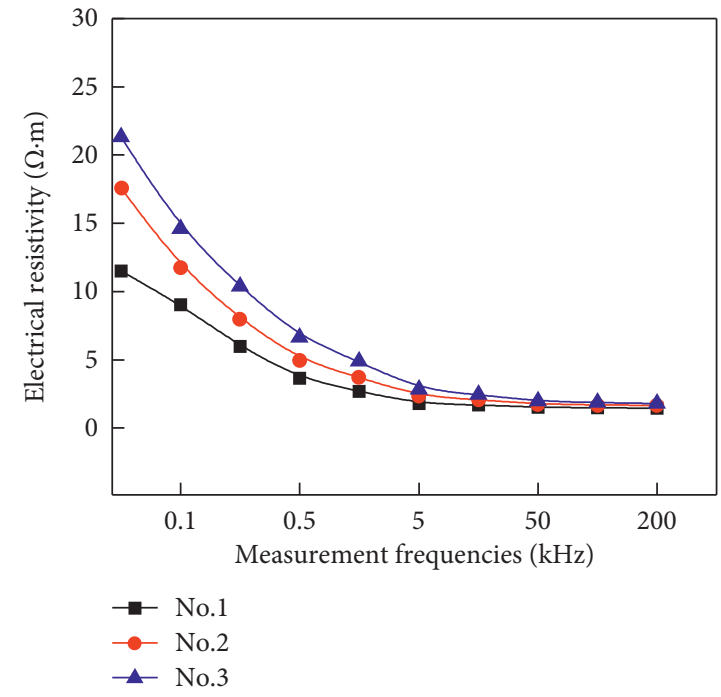

FIgURE 12: The electrical resistivity measurement curves of the HWBM with the $W / C$ of $4: 1$.

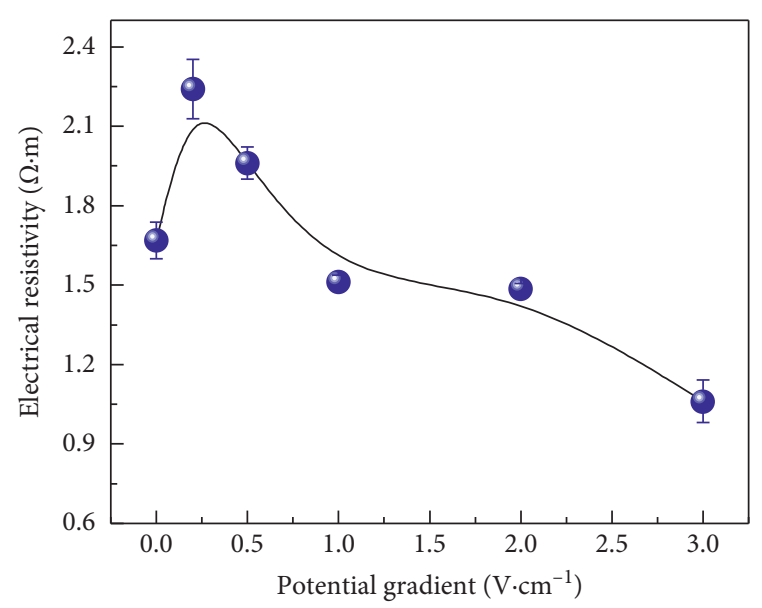

(a)

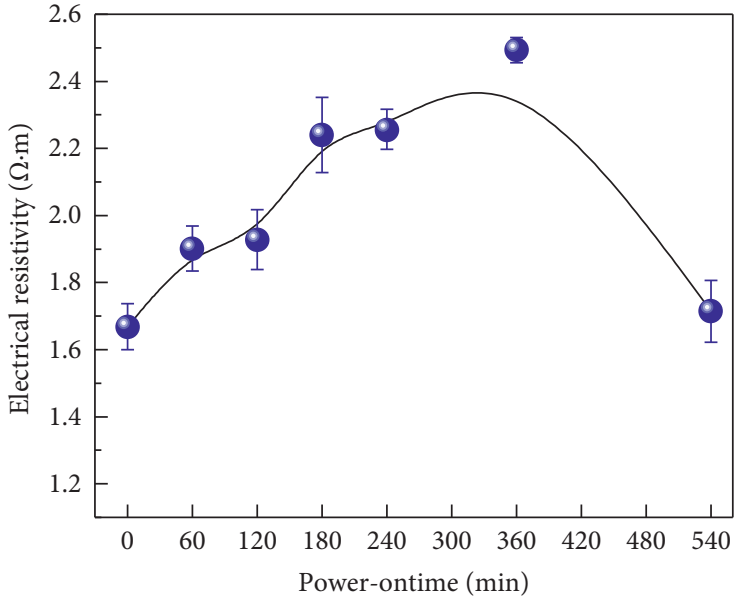

(b)

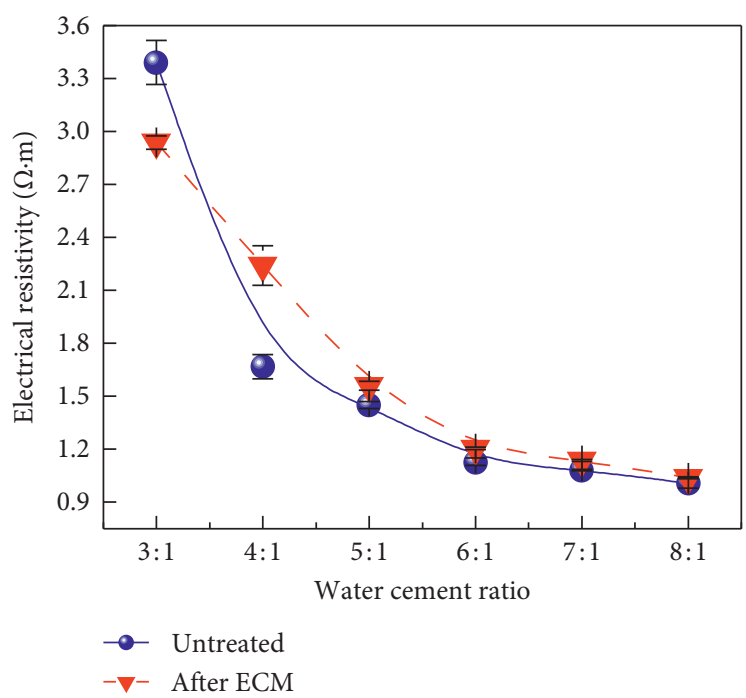

(c)

FIGURE 13: The change in electrical resistivity of the HWBM samples after electrochemical modification: (a) potential gradient; (b) power-on time; and (c) $W / C$. 


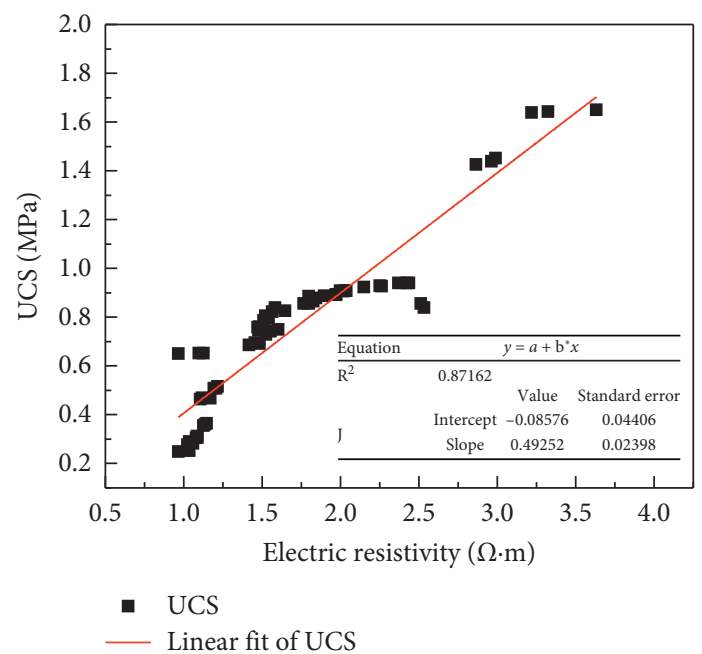

FIGURE 14: The correlation between the electrical resistivity and UCS of the HWBM.

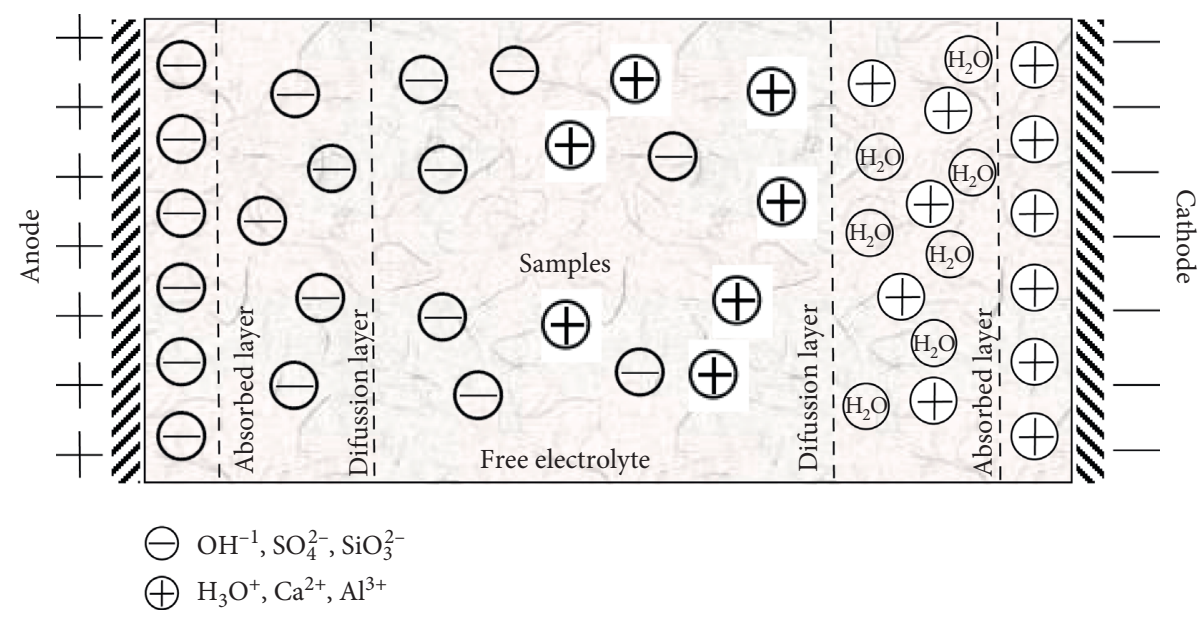

FIGURE 15: A schematic diagram of the migration of internal ions and free water in the HWBM under the electric field.

$$
\begin{array}{r}
3 \mathrm{CaO} \cdot 3 \mathrm{Al}_{2} \mathrm{O}_{3} \cdot \mathrm{CaSO}_{4}+18 \mathrm{H}_{2} \mathrm{O} \longrightarrow \\
3 \mathrm{CaO} \cdot \mathrm{Al}_{2} \mathrm{O}_{3} \cdot \mathrm{CaSO}_{4} \cdot 12 \mathrm{H}_{2} \mathrm{O}+2\left(\mathrm{Al}_{2} \mathrm{O}_{3} 3 \mathrm{H}_{2} \mathrm{O}\right) \\
3 \mathrm{CaO}+\mathrm{Al}_{2} \mathrm{O}_{3} \cdot 3 \mathrm{H}_{2} \mathrm{O}+3\left(\mathrm{CaSO}_{4} \cdot 2 \mathrm{H}_{2} \mathrm{O}\right)+23 \mathrm{H}_{2} \mathrm{O} \longrightarrow \\
3 \mathrm{CaO} \cdot \mathrm{Al}_{2} \mathrm{O}_{3} \cdot 3 \mathrm{CaSO}_{4} \cdot 32 \mathrm{H}_{2} \mathrm{O}
\end{array}
$$

Meanwhile, the increase of water content of the HWBM will lead to the increase of water-cement ratio, which further leads to the microstructure of ettringite be loose and the strength of HWBMs to decrease. Additionally, the elastic modulus of the HWBM will decrease. Oppositely, the UCS, deformation modulus, and elastic modulus of the HWBM will increase when the $W / C$ decreased as described in Section 3.1.3 [1, 55].

The above results show that the ion concentration and water content are important factors affecting the hydration process in HWBMs. Thus, the migration of charged particles such as ions and polar water molecules will affect the hydration process of HWBMs under the DC electric field, which will lead to the change of UCS, deformation modulus, elastic modulus, and electrical resistivity of HWBMs. Therefore, the influence mechanism of electrochemical modification on the internal hydration process of HWBMs needs to be further analyzed and investigated.

\subsection{Effects of Electrochemical Modification on the Hydration} Process of the HWBM. As shown in Figure 15, the electric double layer theory is utilized to explain the effect of electrokinetic effects on the hydration process of the HWBM under the direct current electric field $[56,57]$. Firstly, under the DC electric field, the electrokinetic effects, which include electroosmosis, electrophoresis, and electromigration, caused the directed migration of charged particles such as ion, polar water molecule, and other charged particles in the 
HWBM. Under the effect of electrokinetic, polar water molecules migrate from the anodic region to the cathodic region and flock together near the cathode electrode. It will lead to the change of $W / C$ in the anodic and cathodic regions of the HWBM samples. Additionally, the negative anion transfers to the anode region and forms a double layer structure at the interface between the electrode and the sample, which leads to the increase of $\mathrm{pH}$ value in the anode region and the increase of sulfate ion and silicate ion content, promoting the formation of ettringite and aluminum gel, which promotes the hydration process in the anode region of HWBMs. On the other hand, in the cathode region, the $\mathrm{pH}$ value decreases, and the accumulation of water dipoles increases the water-cement ratio and slows down the hydration rate in the cathode region of HWBM samples. This process leads to the increase of the strength in the anodic region and the decrease of the strength in the cathodic region of the HWBM samples.

However, the formation of ettringite is mainly affected by ion concentration, temperature, and $\mathrm{pH}$ value [58] while the content and structure of ettringite are important factors affecting the mechanic properties of HWBMs $[1,55]$. Hence, it can be inferred that with the increase of the potential gradient and power-on time, the difference of ion concentration, water content, and $\mathrm{pH}$ value in different regions of HWBM increases, which leads to the difference of hydration process and hydration product increases in different regions of HWBM; then, it leads to the mechanic properties of different regions change. Finally, the mechanic properties of HWBMs increase first and then decrease with the increase of the potential gradient and power-on time as described in Sections 3.1 and 3.2, This result is consistent with the previous study in the electrochemical modification of the flyash cemented backfill materials. [39]. Additionally, the order in which the three factors affect the mechanic properties of the HWBM is $W / C>$ potential gradient $>$ power-on time. Therefore, it is very important to determine the appropriate electrochemical parameters for improving the mechanic properties of HWBMs in the engineering applications.

Meanwhile, with the increase of the hydration products and the formation of internal curing structure in the HWBM, the porosity of HWBMs decreased and a large number of water molecules exist in the form of crystal water. And calcium ion, aluminum ion, sulfate ion, and silicate ion also were involved in the hydration reaction, which leads to the decreasing of free water content and ion concentration in the sample. Therefore, with the hydration process, the electric resistivity and UCS of HWBMs increases, Hence, there is a positive correlation between the UCS and electric resistivity of HWBMs.

In summary, under the action of hydration reaction and electrokinetic effect, the UCS and electric resistivity of HWBMs show almost the same trend with the variations of the potential gradient, power-on time, and $W / C$. This result also proves that electrochemical modification is a potential method to modify the mechanic properties of HWBMs. However, numerous experiments need to be performed to investigate the effects of different electrochemical parameters (such as the potential gradient, power-on time, electrode material, electrolyte type and concentration, and $\mathrm{pH}$ value) on the electrochemical modification efficiency of HWBMs. Additionally, the effects of electrochemical treatment on the performance in different regions of HWBM also need to be explored. Furthermore, the electrochemical modified mechanism of HWBMs also needs to be further explored, which can provide a laboratory test and theoretical basis for promoting the engineering application of HWBMs.

4.3. Potential Application of Electrochemical Treatment in the High Water Backfill Materials. Combined with previous studies $[39,41,42]$ and this work, it can be found that the electrochemical method is a potential technology for enhancing the performance of HWBM. Nevertheless, there are many problems that have to be solved before the engineering application. For example, the electrochemical modification mechanism of HWBMs is not clear at present, and the influence of different electrochemical parameters on the performance of HWBM in different regions still needs to be analyzed and explored through a large number of experiments to improve electrochemical modification efficiency and reduce energy consumption. In addition, for further reducing the filling cost, electrochemical modification of HWBM incorporated with solid waste (such as coal gangue and fly ash) also need to be investigated in the future, Meanwhile, before the practical engineering application of electrochemical modification in filling mining, there are many technology problems that also need to be studied in the future, for example, the selection of electrochemical modification equipment in large scale engineering site, the selection of electrode materials and other electrochemical parameters, arrangement mode of the electrode, the safety evaluation in engineering application of electrochemical modification of HWBMs, and the evaluation of modification efficiency and stability in practical application. Additionally, the inhomogeneity of the mechanic properties of the HWBMs after electrochemical treatment and its mechanism also need to be further investigated and solved.

\section{Conclusions}

In this paper, a series of experiments on electrochemical modification of the early age HWBMs were performed and also the influence of potential gradient and power-on time on electrochemical modification efficiency of HWBM and the effects of electrochemical modification on mechanic properties of HWBM with different W/C. The main conclusions are as follows:

(1) As the potential gradient increases, the UCS, deformation modulus, and elastic modulus of the HWBM first increased and then decreased after electrochemical modification. The extreme points appeared at the potential gradient of $0.2 \mathrm{~V} / \mathrm{cm}$. They indicate that the potential gradient of $0.2 \mathrm{~V} / \mathrm{cm}$ can effectively enhance the strength, deformation modulus, and elastic modulus of the HWBMs.

(2) With the increase of power-on time, the UCS, deformation modulus, and elastic modulus of HWBMs 
also first increased and then decreased after electrochemical modification. However, the peak point of UCS occurred in the power-on time of $6 \mathrm{~h}$ while the peak points of deformation modulus and elastic modulus occurred in the power-on time of $3 \mathrm{~h}$.

(3) With the increase of the $W / C$, the UCS of the HWBM increased obviously after electrochemical modification except when the $W / C$ was $3: 1$. However, the deformation modulus and elastic modulus of the HWBMs decreased except when the $W / C$ was $4: 1$. Hence, the electrochemical technology is a potential method to alter the mechanic properties of the HWBMs in engineering application.

(4) There is a linear positive correlation between the UCS and electrical resistivity in the HWBM. But a number of experiments still should be performed to confirm this correlation and explore its mechanism. It indicates that the electrical resistivity of HWBM is a potential parameter for evaluating its compressive strength.

\section{Data Availability}

We would like to declare that all data, models, or codes generated or used during the study are available from the corresponding author on request (Shengrong Xie, e-mail: xsrxcq@163.com; and Yaohui Sun, email; sun357479936@ 163.com.).

\section{Additional Points}

(1) A novel method for modifying the strength and electrical resistivity of the HWBM by electrochemical treatment was proposed. (2) Influences of the potential gradient and power-on time on the modified effects of HWBM were studied. (3) The effect of electrochemical modification on the mechanical properties and electrical resistivity of HWBMs with different $W / C$ was studied. (4) The positive correlation between electrical resistivity and UCS of HWBMs was performed.

\section{Conflicts of Interest}

The authors declare that they have no conflicts of interest.

\section{Acknowledgments}

This work was financially supported by the China Postdoctoral Science Foundation (2020T130701 and 2019M650895), the National Natural Science Foundation of China (51974317 and 51504259), the Fundamental Research Funds for the Central Universities (2020YJSNY06 and 2010QZ06), and the Yue Qi Young Scholar Project, China University of Mining \& Technology, Beijing (800015Z1104).

\section{References}

[1] J.-P. Zuo, Z.-J. Hong, Z.-Q. Xiong, C. Wang, and H.-Q. Song, "Influence of different W/C on the performances and hydration progress of dual liquid high water backfilling material," Construction and Building Materials, vol. 190, pp. 910-917, 2018.

[2] Y. Wang, J. Yu, J. Wang, and X. Guan, "Effects of aluminum sulfate and quicklime/fluorgypsum ratio on the properties of calcium sulfoaluminate (CSA) cement-based double liquid grouting materials," Materials, vol. 12, no. 8, p. 1222, 2019.

[3] A. Wang, L. Ma, Z. Wang, D. Z. K. Li, Y. Zhang, and X. Yi, "Soil and water conservation in mining area based on ground surface subsidence control: development of a high-water swelling material and its application in backfilling mining," Environmental Earth Sciences, vol. 75, no. 9, p. 779, 2016.

[4] G. Feng, Y. Ding, H. Zhu, and J. Bai, "Experimental research on a superhigh water packing material for mining and its micromorphology," Journal of China University of Mining and Technology, vol. 39, pp. 813-819, 2010.

[5] Y. Ding, G. Feng, and C. Wang, "Experimental research on basic properties of superhigh water packing material," Meitan Xuebao/Journal of the China Coal Society, vol. 36, no. 7, pp. 1087-1092, 2011.

[6] H. Wu, C. Liu, Z. Zhang, and Y. Miao, "Time effect of chloride erosion on physical and mechanical properties of high-watercontent materials," Advances in Materials Science and Engineering, vol. 2020, Article ID 2730283, 2020.

[7] B. Feng, C. Liu, H. Xie, M. Wu, and Y. Jiang, "Experimental study on the size and the shape of high-water-content material that modified. advanced engineering sciences," Gongcheng Kexue Yu Jishu/Advanced Engineering Science, vol. 49, pp. 121-127, 2017.

[8] B. Feng, C. Liu, H. Xie, W. Sun, and Z. Diao, "Experimental study and analysis of the mechanical properties of high-watercontent materials modified with fly ash," Gongcheng Kexue Xuebao/Chinese Journal of Engineering, vol. 40, no. 10, pp. 1187-1195, 2018.

[9] F. Sha, S. Li, R. Liu, Z. Li, and Q. Zhang, "Experimental study on performance of cement-based grouts admixed with fly ash, bentonite, superplasticizer and water glass," Construction and Building Materials, vol. 161, pp. 282-291, 2018.

[10] M. García-Maté, A. G. De La Torre, L. León-Reina, M. A. G. Aranda, and I. Santacruz, "Hydration studies of calcium sulfoaluminate cements blended with fly ash," $\mathrm{Ce}$ ment and Concrete Research, vol. 54, pp. 12-20, 2013.

[11] Y. Zhang, Y. Wang, T. Li, Z. Xiong, and Y. Sun, "Effects of lithium carbonate on performances of sulphoaluminate cement-based dual liquid high water material and its mechanisms," Construction and Building Materials, vol. 161, pp. 374-380, 2018.

[12] Y. Jiang, C. Liu, H. Xie, J. Li, and P. Luo, “Test and analysis of main physical and mechanical parameters of modified highwater-concretion," Journal of Sichuan University (Engineering Science Edition), vol. 47, pp. 65-69, 2015.

[13] M. Wu, C. Liu, Y. Jiang, and B. Feng, "Experimental study on the influence of typical suspension additives on mechanical properties of high-water materials," Advanced Engineering Science, vol. 49, pp. 21-26, 2017.

[14] J. Xia, Q. Su, and D. Liu, "Optimal gypsum-lime content of high water material,” Materials Letters, vol. 215, pp. 284-287, 2018.

[15] C. A. Anagnostopoulos, "Effect of different superplasticisers on the physical and mechanical properties of cement grouts," Construction and Building Materials, vol. 50, pp. 162-168, 2014.

[16] H. Li, X. Guan, X. Zhang, P. Ge, X. Hu, and D. Zou, "Influence of superfine ettringite on the properties of sulphoaluminate 
cement-based grouting materials," Construction and Building Materials, vol. 166, pp. 723-731, 2018.

[17] S. Jayasekera, "Electrokinetics to modify strength characteristics of soft clayey soils: a laboratory based investigation," Electrochimica Acta, vol. 181, pp. 39-47, 2015.

[18] D. Wang, T. Kang, W. Han, and Z. Liu, "Electrochemical modification of tensile strength and pore structure in mudstone," International Journal of Rock Mechanics and Mining Sciences, vol. 48, no. 4, pp. 687-692, 2011.

[19] Z. Chai, Y. Sun, and J. Bai, "Experimental study on pore and strength change of mudstone from the coal measure strata under electro-chemical," Journal of the China Coal Society, vol. 43, no. 3, pp. 667-674, 2018.

[20] D. Wang, T. Kang, Z. Chai, W. Han, and Z. Liu, "Experimental studies of subsidence and expandability of montmorillonitic soft rock particles under electrochemical treatment," Chinese Journal of Rock Mechanics and Engineering, vol. 28, no. 9, pp. 1876-1883, 2009.

[21] L. M. Ottosen and I. V. Christensen, "Electrokinetic desalination of sandstones for $\mathrm{NaCl}$ removal-Test of different clay poultices at the electrodes," Electrochimica Acta, vol. 86, pp. 192-202, 2012.

[22] J. Feijoo, L. M. Ottosen, and J. S. Pozo-Antonio, "Influence of the properties of granite and sandstone in the desalination process by electrokinetic technique," Electrochimica Acta, vol. 181, pp. 280-287, 2015.

[23] J. Feijoo, O. Matyšćák, L. M. Ottosen, T. Rivas, and X. R. Nóvoa, "Electrokinetic desalination of protruded areas of stone avoiding the direct contact with electrodes," Materials and Structures, vol. 50, no. 1, p. 82, 2016.

[24] J. Feijoo, T. Rivas, X. R. Nóvoa, I. Otero, and O. Jorge, "In situ desalination of a granitic column by the electrokinetic method," International Journal of Architectural Heritage, vol. 12, no. 1, pp. 63-74, 2017.

[25] J. Feijoo, T. Rivas, X. R. Nóvoa, and L. M. Ottosen, "New double electrode system for the electrochemical desalination of building stones," International Journal of Architectural Heritage, vol. 14, no. 5, pp. 678-693, 2018.

[26] J. Feijoo, X. R. Nóvoa, T. Rivas, and L. M. Ottosen, "Enhancing the efficiency of electrochemical desalination of stones: a proton pump approach," Materials and Structures, vol. 51, no. 4, p. 100, 2018.

[27] E. Méndez, J. A. García, G. Hernández et al., "Study of electrochemical removal of phenanthrene in bentonite clay by physicochemical indicators," Separation and Purification Technology, vol. 208, pp. 92-99, 2019.

[28] J. Q. Shang, E. Mohamedelhassan, and M. Ismail, "Electrochemical cementation of offshore calcareous soil," Canadian Geotechnical Journal, vol. 41, no. 5, pp. 877-893, 2004.

[29] S. R. Kaniraj and J. H. S. Yee, "Electro-osmotic consolidation experiments on an organic soil," Geotechnical and Geological Engineering, vol. 29, no. 4, pp. 505-518, 2011.

[30] J. Wang, J. Ma, F. Liu et al., "Experimental study on the improvement of marine clay slurry by electroosmosis-vacuum preloading," Geotextiles and Geomembranes, vol. 44, no. 4, pp. 615-622, 2016.

[31] Z. Xue, X. Tang, Q. Yang, Z. Tian, Y. Zhang, and W. Xu, "Mechanism of electro-osmotic chemical for clay improvement: process analysis and clay property evolution," Applied Clay Science, vol. 166, pp. 18-26, 2018.

[32] A. H. Vakili, M. Kaedi, M. Mokhberi, M. R. B. Selamat, and M. Salimi, "Treatment of highly dispersive clay by lignosulfonate addition and electroosmosis application," Applied Clay Science, vol. 152, pp. 1-8, 2018.
[33] L. Zhang and L. Hu, "Laboratory tests of electro-osmotic consolidation combined with vacuum preloading on kaolinite using electrokinetic geosynthetics," Geotextiles and Geomembranes, vol. 47, no. 2, pp. 166-176, 2019.

[34] L. Hu, L. Zhang, and $\mathrm{H}$. Wu, "Experimental study of the effects of soil $\mathrm{pH}$ and ionic species on the electro-osmotic consolidation of kaolin," Journal of Hazardous Materials, vol. 368, pp. 885-893, 2019.

[35] J. Guo, T. Kang, J. Kang, Z. Chai, and G. Zhao, “Accelerating methane desorption in lump anthracite modified by electrochemical treatment," International Journal of Coal Geology, vol. 131, pp. 392-399, 2014.

[36] M. X. Hou, X. Y. Zhang, T. Kang et al., "Experimental study on electrochemical enhancement of water absorption of anthracite absorption of anthracite," Journal of the China Coal Society, vol. 2019, 2019.

[37] X. Zhang, R. Zhang, T. Kang, and Y. Hu, “The adsorption and desorption behavior of $\mathrm{CH} 4$ on jincheng anthracite modified in $\mathrm{Fe}^{3+}$ and $\mathrm{Cu}^{2+}$ ion electrolytes," Energy \& Fuels, vol. 34, no. 2, pp. 1251-1258, 2020.

[38] X. Zhang, R. Zhang, T. Kang, Y. Hu, and C. Li, "Experimental and mechanistic research on methane adsorption in anthracite modified by electrochemical treatment using selected electrode materials," Scientific Reports, vol. 9, no. 1, Article ID 17163, 2019.

[39] B. Yin, T. Kang, J. Kang, and Y. Chen, "Experimental and mechanistic research on enhancing the strength and deformation characteristics of fly-ash-cemented filling materials modified by electrochemical treatment," Energy \& Fuels, vol. 32, no. 3, pp. 3614-3626, 2018.

[40] A. B. Fourie and C. J. F. P. Jones, "Improved estimates of power consumption during dewatering of mine tailings using electrokinetic geosynthetics (EKGs)," Geotextiles and Geomembranes, vol. 28, no. 2, pp. 181-190, 2010.

[41] X. Cai, Z. He, Y. Shao, and H. Sun, "Macro- and microcharacteristics of cement binders containing high volume fly ash subject to electrochemical accelerated leaching," Construction and Building Materials, vol. 116, pp. 25-35, 2016.

[42] L. B. Yu, L. H. Jiang, H. Q. Chu, M. Z. Guo, Z. Y. Zhu, and H. Dong, "Effect of electrochemical chloride removal and ground granulated blast furnace slag on the chloride binding of cement paste subjected to $\mathrm{NaCl}$ and $\mathrm{Na}_{2} \mathrm{SO}_{4}$ attack," Construction and Building Materials, vol. 220, pp. 538-546, 2019.

[43] M. Li, A. Li, J. Zhang, Y. Huang, and J. Li, "Effects of particle sizes on compressive deformation and particle breakage of gangue used for coal mine goaf backfill," Powder Technology, vol. 360, pp. 493-502, 2020.

[44] M. Li, J. Zhang, G. Meng, Y. Gao, and A. Li, "Testing and modelling creep compression of waste rocks for backfill with different lithologies," International Journal of Rock Mechanics and Mining Sciences, vol. 125, Article ID 104170, 2020.

[45] S. Y. Liu, Y. J. Du, L. H. Han, and M. F. Gu, "Experimental study on the electrical resistivity of soil-cement admixtures," Environmental Geology, vol. 54, no. 6, pp. 1227-1233, 2008.

[46] Z. T. Bieniawski and M. J. Bernede, "Suggested methods for determining the uniaxial compressive strength and deformability of rock materials," International Journal of Rock Mechanics and Mining Sciences of Geomechanics Abstracts, vol. 16, no. 2, p. 137, 1979.

[47] S. Zhang, Y. Li, X. Kou, and X. Dong, "Study of electrical resistivity and strength characteristics of zinc contaminated soil solidified by cement," Rock and Soil Mechanics, vol. 36, no. 10, pp. 2899-2906, 2015. 
[48] X. Dong, S. Zhang, N. Su, and X. Huang, "Effects of contaminated soil on electrical resistivity and strength of cemented soil," China Civil Engineering Journal, vol. 48, no. 4, pp. 91-98, 2015.

[49] G. Kibria, S. Hossain, and M. S. Khan, "Determination of consolidation properties using electrical resistivity," Journal of Applied Geophysics, vol. 152, pp. 150-160, 2018.

[50] N. Sabbağ and O. Uyanık, "Determination of the reinforced concrete strength by apparent resistivity depending on the curing conditions," Journal of Applied Geophysics, vol. 155, pp. 13-25, 2018.

[51] W. Xu, X. Tian, Y. Qiu, P. Dang, and T. Yin, "Experiment of the resistivity characteristic of cemented backfill mass during the whole consolidation process," Journal of China University of Mining and Technology, vol. 46, pp. 265-344, 2017.

[52] B. Yin, T. Kang, J. Kang, Y. Chen, L. Wu, and M. Du, "Investigation of the hydration kinetics and microstructure formation mechanism of fresh fly ash cemented filling materials based on hydration heat and volume resistivity characteristics," Applied Clay Science, vol. 166, pp. 146-158, 2018.

[53] M. T. Palou and J. Majling, "Effects of sulphate, calcium and aluminum ions upon the hydration of sulphoaluminate belite cement," Journal of Thermal Analysis, vol. 46, no. 2, pp. 549-556, 1996.

[54] L. L. Xu, P. M. Wang, G. M. Wu, and G. F. Zhang, "Effect of calcium sulfate on the formation of ettringite in calcium aluminate and sulfoaluminate blended systems," Key Engineering Materials, vol. 599, pp. 23-28, 2014.

[55] X. Li and C. Liu, "Mechanical properties and damage constitutive model of high water material at different loading rates," Advanced Engineering Materials, vol. 20, no. 6, p. 1701098, 2018.

[56] Y. Acar, R. Gale, A. Alshawabkeh et al., "Electrokinetic remediation: basics and technology status," Journal of Hazardous Materials, vol. 40, pp. 117-137, 1996.

[57] Z. Yu, H. Li, X. Liu, C. Xu, and H. Xiong, "Influence of soil electric field on water movement in soil," Soil and Tillage Research, vol. 155, pp. 263-270, 2016.

[58] J. Qian, J. Yu, H. Sun, and Y. Ma, "Formation and function of ettringite in cement hydrates," Journal of the Chinese Ceramic Society, vol. 45, pp. 1569-1581, 2017. 